\title{
Rancang Bangun Sistem Kontrol Gorden, Lampu, dan Kipas Angin Berbasis Arduino Uno R3
}

\author{
Alisman*, Wildian \\ Jurusan Fisika FMIPA Universitas Andalas \\ Kampus Unand Limau Manis, Padang, 25163, Indonesia \\ *Alismanbnalihasan@gmail.com
}

\begin{abstract}
ABSTRAK
Telah dilakukan sebuah rancang bangun prototipe sistem kontrol gorden, lampu, dan kipas angin ruangan berbasis Arduino Uno R3. Gorden diruangan terbuka atau tertutup dan lampu hidup atau mati secara otomatis berdasarkan pendeteksian cahaya luar ruangan oleh sensor LDR (Light Dependent Resistor). Gerak buka-tutup gorden tipe vertical blind ini dilakukan melalui mekanisme putaran motor stepper 5V. Suhu dan kelembaban ruangan dideteksi oleh sensor DHT22 untuk pengontrolan kipas angin. Nilai suhu dan kelembaban ditampilkan pada LCD 2x16. Hasil uji ini menunjukkan bahwa sistem otomatis yang dikontrol dengan mikrokontroler ATmega328 dapat bekerja sesuai dengan algoritma yang dirancang. Kata kunci : Sensor, Intensitas cahaya, vertical blind, kelembaban relatif, suhu, motor stepper
\end{abstract}

\section{ABSTRACT}

A design of the prototype of room curtain, lamp, and fan control system based on Arduino Uno R3 has been carried out. Curtains in the room opened or closed and the lamp turn on or off automatically based on outdoor light intensity which detected by LDR (Light Dependent Resistor) sensor. Vertical blind curtain opening and closing motion is carried out through the mechanism of $5 \mathrm{~V}$ stepper motor rotation. The temperature and humidity of the room are detected by the DHT22 sensor for controlling the fan. Temperature and humidity values are displayed on LCD 2x16. The results of the test indicate that an automated system controlled by the ATmega328 microcontroller work properly accordance to the algorithm that has been designed.

Keywords : Sensor, light intensity, vertical blind, relative humidity, suhu, stepper motor

\section{PENDAHULUAN}

Setiap aktivitas keseharian seseorang membutuhkan tempat atau ruangan yang nyaman agar dapat meningkatkan konsentrasi pada suatu bidang yang dikerjakannya. Salah satu faktor kenyamanan dalam beraktivitas pada ruangan ditentukan oleh keadaan temperatur dan kelembaban tempat dimana proses tersebut dilakukan. Temperatur dan kelembaban ruangan sangat berpengaruh pada efektifitas kegiatan atau bahkan dalam bekerja. Bekerja pada lingkungan yang terlalu panas atau terlalu lembab, dapat menyebabkan keletihan terlalu dini sedangkan pada lingkungan yang terlalu lembab, dapat menyebabkan hilangnya fleksibilitas terhadap alat-alat motorik tubuh yang disebabkan oleh timbulnya kekakuan fisik tubuh (Nainggolan dan Yusfi, 2013).

Berdasarkan penelitian yang dilakukan Marsidi dan Kusmindari (2009) bahwa semakin tinggi temperatur udara, maka semakin tinggi juga pengaruh kelembaban udara terhadap tubuh manusia dan jika semakin besar pengaruh temperatur dan kelembaban udara tersebut maka dapat mengakibatkan perubahan laju detak jantung. Aktivitas dalam ruangan dapat dilakukan secara optimal pada temperatur udara ruangan $27^{\circ} \mathrm{C}$ dan kelembaban udara yang optimal adalah dibawah 40\%. Berdasarkan Keputusan Menteri Kesehatan Republik Indonesia (KEPMENKES) Nomor 1405/Menkes/SK/XI/2002 mengenai persyaratan kesehatan lingkungan kerja perkantoran dan industri, bahwa persyaratan udara ruangan yang baik memiliki range temperatur berkisar $18^{\circ} \mathrm{C}-28{ }^{\circ} \mathrm{C}$ dan kelembaban udara $40 \%-60 \%$. Saat kondisi temperatur di atas $28^{\circ} \mathrm{C}$ diperlukan alat pengkondisi udara ruangan seperti kipas angin atau Air Conditioner (AC), sehingga dapat menciptakan kondisi ruangan yang layak dan nyaman untuk beraktivitas.

Aktivitas yang biasa dilakukan oleh beberapa orang di rumah tangga ataupun di kantor saat pagi dan malam hari salah satunya yaitu membuka dan menutup gorden secara manual, dan biasanya seseorang sering lupa menutup gorden pada saat bepergian dari pagi hingga malam hari. Ruangan yang ditinggal lama dengan kondisi gorden yang tertutup juga berpengaruh pada temperatur dan kelembaban ruangan, dikarenakan tidak adanya cahaya matahari yang masuk kedalam ruangan tersebut. Lidiawati dkk., (2013) telah merancang sistem otomatisasi lampu, 
tirai, dan kipas angin menggunakan mikrokontroler untuk menghemat energi listrik. Alat yang dihasilkan dari penelitian ini adalah alat yang dapat membuat lampu, tirai dan kipas angin bekerja secara otomatis. Penelitian tersebut tidak menggunakan sensor temperatur dan kelembaban untuk mengoptimalkan kinerja dari kipas angin sebagai pengkondisi temperatur diruangan. Penelitian ini hanya menggunakan tirai geser biasa, yang mana tidak terlalu menjaga privasi dari penggunanya.

Ahmad dan Dharmawan (2011) melakukan penelitian pada sistem otomatis buka tutup tirai berbasis Light Dependent Resistor (LDR). Pada penelitian ini sistem otomatis yang dihasilkan untuk mengontrol membuka dan menutup tirai berdasarkan masukan dari LDR dan Real Time Clock (RTC). Penelitian ini hanya terfokus pada otomatisasi tirai dan tidak menggunakan pengkondisi temperatur dan kelembaban udara pada ruangan.

Berdasarkan penelitian yang telah dilakukan sebelumnya untuk mengukur kelembaban dan temperatur ruangan, serta perkembangan teknologi pada sistem kontrol otomatis yang berkembang saat ini, menjadi landasan untuk melakukan penelitian tentang perancangan sistem kontrol gorden, lampu, dan kipas angin berbasis Arduino Uno R3. Sistem kontrol ini memanfaatkan kinerja motor stepper sebagai penggerak buka tutup gorden dan DHT22 sebagai sensor temperatur dan kelembaban udara dalam ruangan dengan kipas angin sebagai pengkondisi temperatur dan kelembaban, serta LDR sebagai sensor cahaya. Perancangan software pada penelitian ini menggunakan bahasa $\mathrm{C}$ yang ditanamkan pada Arduino Uno. Alat ini diharapkan dapat mempermudah pengguna ruangan dalam menyesuaikan cahaya, temperatur dan kelembaban udara ruangan sehingga lebih meningkatkan efisiensi waktu dan kenyamanan pengguna didalamnya, serta meminimalisir kerusakan yang terjadi pada gorden.

\section{METODE}

\subsection{Diagram Blok Sistem}

Sistem kontrol buka tutup gorden, lampu otomatis, dan kipas angin ini dikontrol dengan menggunakan Arduino Uno R3. Arus yang terbaca pada sensor LDR dan DHT22 akan diproses oleh Arduino dengan program yang telah ditanamkan. Berikut tampilan diagram blok sistem pada Gambar 1.

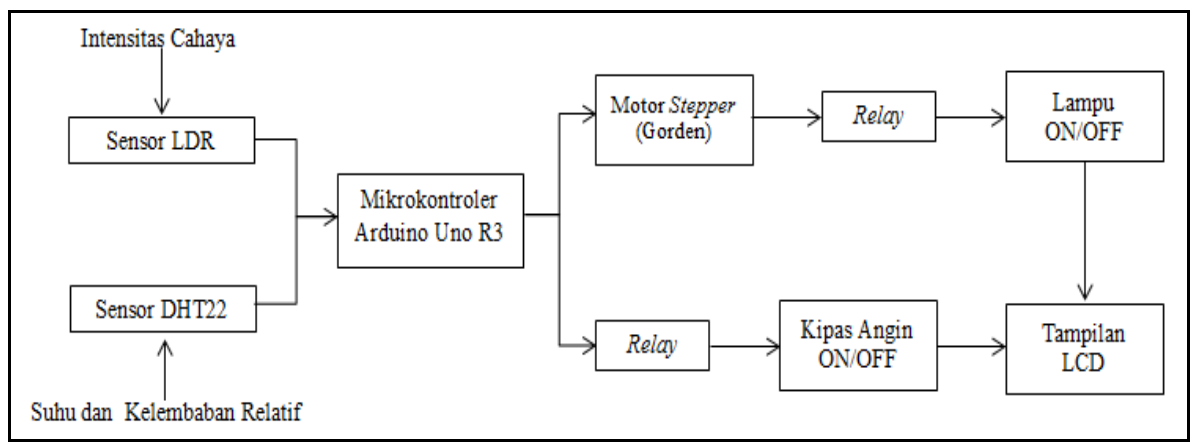

Gambar 1 Diagram blok sistem

Intensitas cahaya diindra oleh sensor LDR pada awal sistem bekerja. Motor stepper bekerja dalam membuka gorden. Sensor DHT22 mendeteksi suhu dan kelembaban relatif di dalam ruangan. Mekanisme kerja relay untuk menghidup atau mematikan lampu dan kipas angina. Keseluruhan sistem di kontrol oleh Arduino Uno R3 dan hasil data ditampilkan pada LCD.

\subsection{Rancangan Sistem Perangkat Keras (Hardware)}

Perancangan hardware bertujuan untuk menguji rangkaian-rangkain yang digunakan. Sistem hardware ini terdiri dari beberapa piranti elektronik yang terhubung langsung dengan Arduino sebagai pusat pengolahan data yang berkaitan dengan input dan output sistem. Adapun piranti yang digunakan sebagai input adalah sensor LDR, sensor DHT22 dan motor stepper. Sedangkan piranti output adalah LCD 2x16 sebagai penampil data dan relay sebagai saklar otomatis. Skematik rangkaian secara keseluruhan ditunjukkan oleh Gambar 2. 


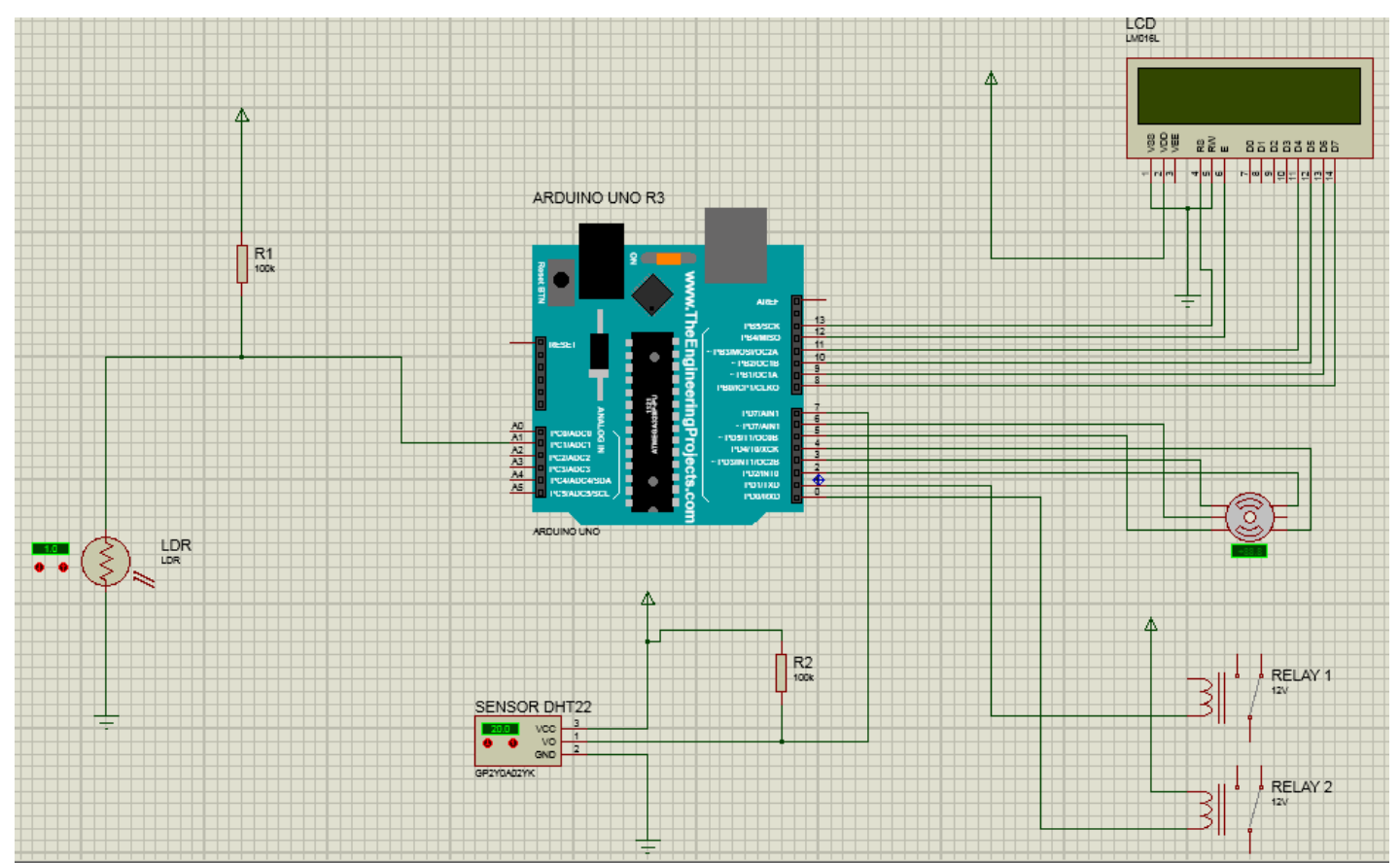

Gambar 2 Rancangan sistem hardware

\subsection{Rancangan Bentuk Fisik Alat}

Bentuk fisik alat yang dirancang berupa prototipe ruangan yang berukuran $0,5 \mathrm{~m} \times 0,5$ $\mathrm{m}$, pada prototipe ini dipasang lampu dan kipas angin, serta sistem kontrol. Berikut bentuk rancangan prototipe yang diperlihatkan pada Gambar 3.

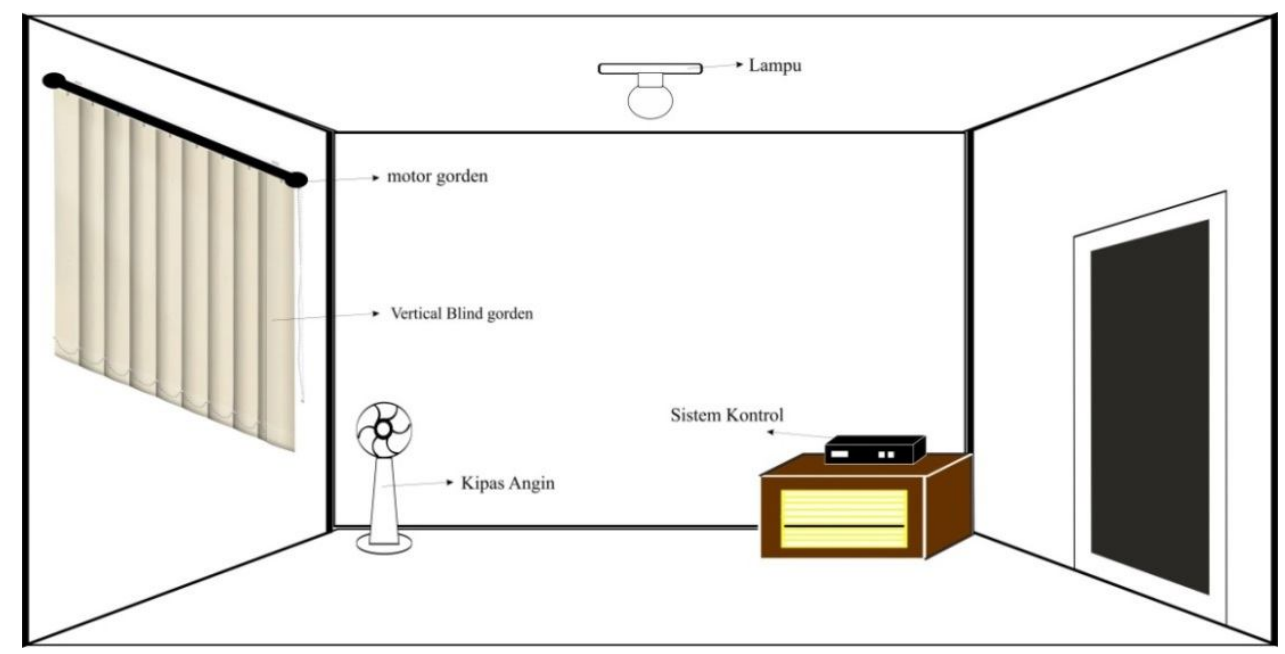

Gambar 3 Posisi sistem kontrol dalam ruangan

Gambar 3 menjelaskan posisi vertical blind gorden, lampu, kipas angin dan sistem kontrol. Sensor DHT22 ditempatkan pada posisi yang memudahkan sensor mendeteksi suhu dan kelembaban relatif di dalam ruangan. Sensor LDR yang berada pada sistem kontrol dipasang menghadap ke sumber cahaya alami.

\subsection{Diagram Alir}

Sistem kontrol alat ini terbagi menjadi dua sistem kerja. Sistem pertama pada perangkat lunak Arduino Uno diawali dari sensor LDR mendeteksi cahaya, kemudian apabila intensitas cahaya yang dideteksi besar sama dengan 100 Lux maka lampu ruangan akan mati dan motor stepper bergerak membuka gorden. Jika intensitas cahaya yang dideteksi kecil sama dengan 100 Lux pada pembacaan LDR, maka lampu akan hidup dan gorden akan menutup. Sistem kerja tersebut ditampilkan dalam bentuk digram alir seperti pada Gambar 4. 


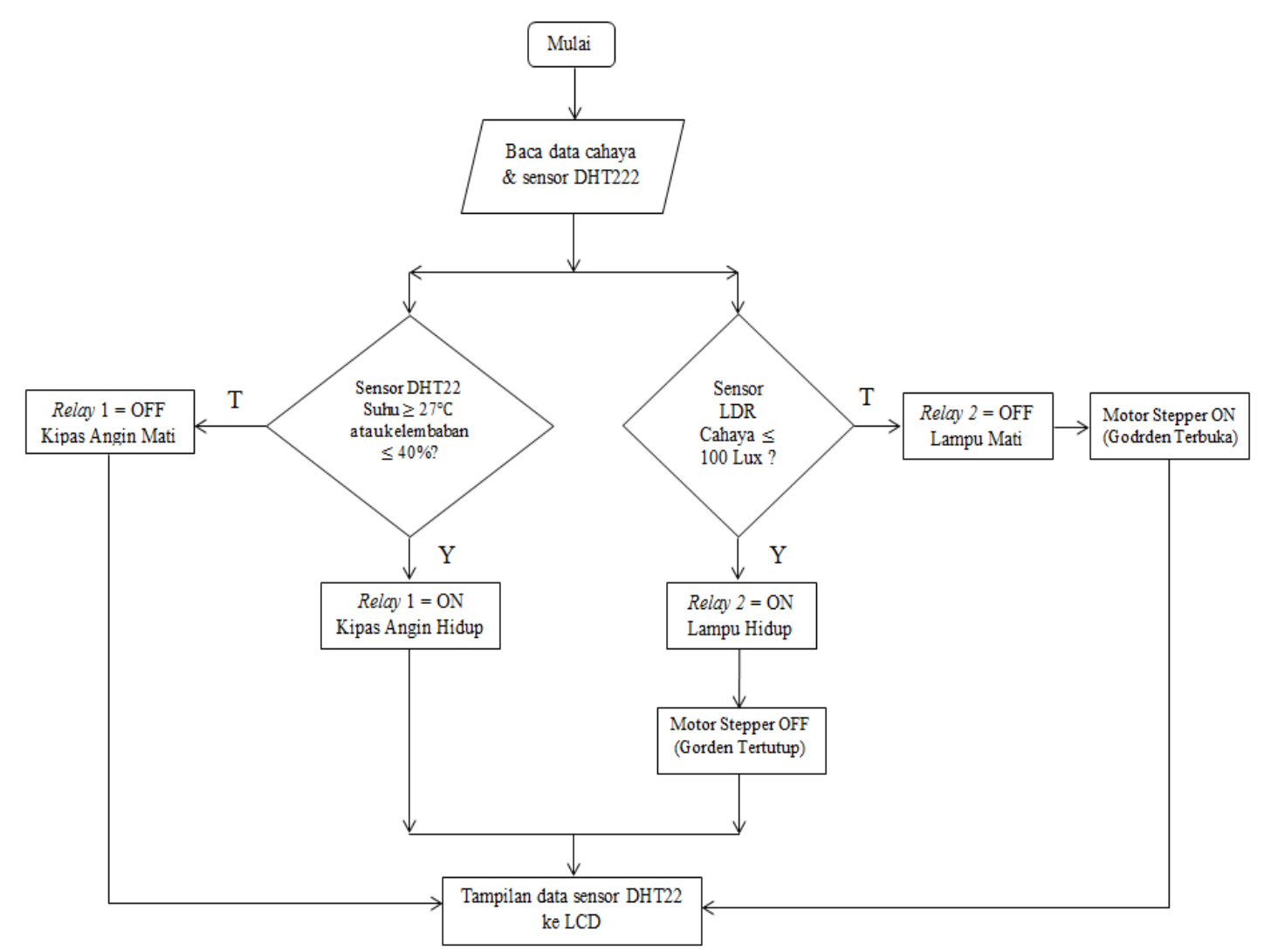

Gambar 4 Diagram alir penelitian

Sistem kedua sensor DHT22 mendeteksi suhu dan kelembaban relatif udara. Hasil pendeteksian suhu besar sama $27^{\circ} \mathrm{C}$ atau kelembaban berada besar sama $40 \%$ seperti yang ditanamkan di dalam program maka kipas angin akan hidup untuk mengkondisikan suhu dan kelembaban udara diruangan.

\section{HASIL DAN DISKUSI}

\subsection{Karakterisasi Sensor DHT22}

Karakterisasi pada kemampuan sensor DHT22 dilakukan saat kondisi suhu ruangan normal dimana tidak ada perlakuan khusus terhadap udara di dalam ruangan. Hasil karakterisasi serta pengukuran sensor DHT22 dengan Lutron HT-3006HA, dan \% error untuk kondisi ruangan normal diperlihatkan pada Tabel 1.

Tabel 1 Karakterisasi sensor DHT22

\begin{tabular}{ccccccc}
\hline \multirow{2}{*}{ No } & \multicolumn{2}{c}{ Sensor DHT22 } & \multicolumn{2}{c}{ Lutron HT-3006HA } & \multicolumn{2}{c}{$\%$ Error } \\
\cline { 2 - 7 } & $\mathbf{R H ~ ( \% )}$ & $\mathbf{T}\left({ }^{\circ} \mathbf{C}\right)$ & $\mathbf{R H ~}(\boldsymbol{\%})$ & $\mathbf{T}\left({ }^{\circ} \mathbf{C}\right)$ & $\mathbf{R H}$ & $\mathbf{T}$ \\
\hline 1. & 76,4 & 26,8 & 81,9 & 28,7 & 6,7155 & 6,6202 \\
2. & 74,7 & 27,0 & 81,7 & 28,8 & 7,3439 & 6,2500 \\
3. & 74,9 & 28,6 & 81,4 & 28,9 & 7,9853 & 1,0381 \\
4. & 74,1 & 28,8 & 80,9 & 29,0 & 8,4054 & 0,6897 \\
5. & 73,5 & 28,9 & 80,5 & 29,1 & 8,6957 & 0,6873 \\
6. & 72,5 & 29,1 & 80,1 & 29,2 & 9,4881 & 0,3425 \\
7. & 72,0 & 29,3 & 79,7 & 29,4 & 9,6612 & 0,3401 \\
8. & 71,3 & 29,3 & 79,4 & 29,5 & 10,202 & 0,6780 \\
9. & 70,9 & 29,5 & 79,2 & 29,7 & 10,480 & 0,6734 \\
10. & 72,5 & 80,1 & 29,9 & 9,4881 & 0,6689 \\
\hline \multicolumn{6}{c}{ Rata-rata persen error } \\
\hline
\end{tabular}

Error rata-rata dari hasil perbandingan sensor DHT22 dengan alat pembanding Lutron HT-3006HA sebesar 8,8465\% untuk kelembaban dan 1,7988\% untuk suhu. Data yang diperoleh 
dari kemampuan pengukuran sensor DHT22 dengan alat pembanding mendekati nilai yang dihasilkan oleh alat pembanding berupa bilangan desimal 1 angka di belakang koma, sesuai kemampuan alat pembanding dalam pengukuran suhu dan kelembaban dengan nilai desimal 1 angka di belakang koma. Hasil yang didapatkan dari pembacaan suhu oleh sensor DHT22 tidak terlalu linier dengan besar linearitas yang diperoleh sebesar 0,9859. Nilai kemiringan garis yang didapatkan sebesar 0,7096 dan nilai awalnya sebesar 8,5701. Berikut grafik perbandingan suhu pada kondisi normal seperti yang diperlihatkan pada Gambar 5.

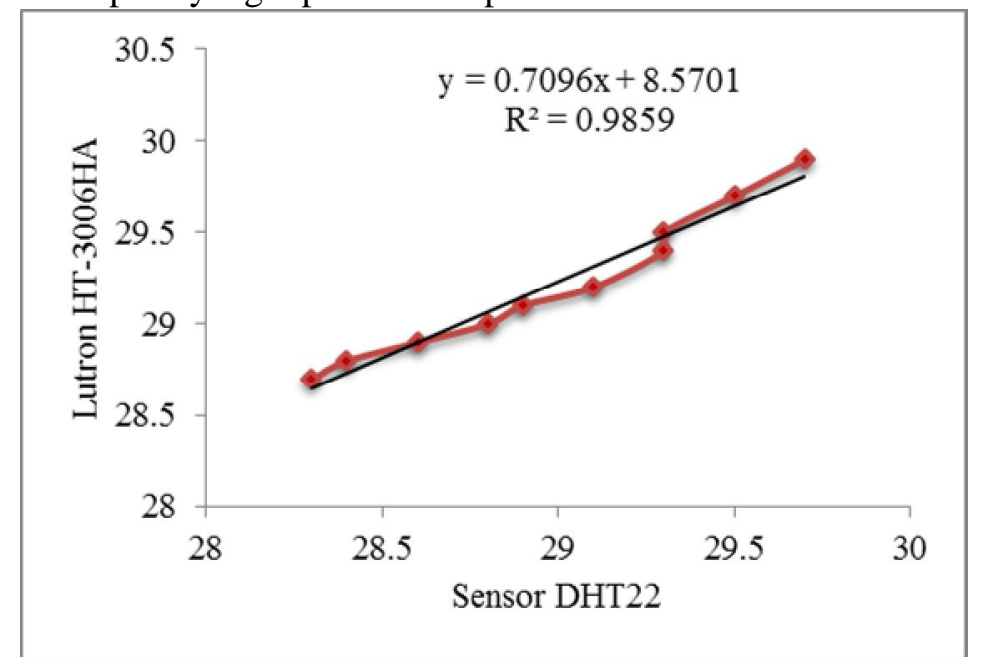

Gambar 5 Grafik perbandingan suhu pada kondisi normal

Grafik yang diperlihatkan pada Gambar 6 merupakan perbandingan kelembaban relatif yang diperoleh setelah pengukuran sensor DHT22 dengan alat pembanding Lutron HT3006HA. Dari pengukuran tersebut terlihat bahwa nilai pembacaan sensor cukup linear dengan linearitas yang didapatkan sebesar 0,9471, dan besar nilai kemiringan garisnya 0,6432 dengan nilai awal 33,214.

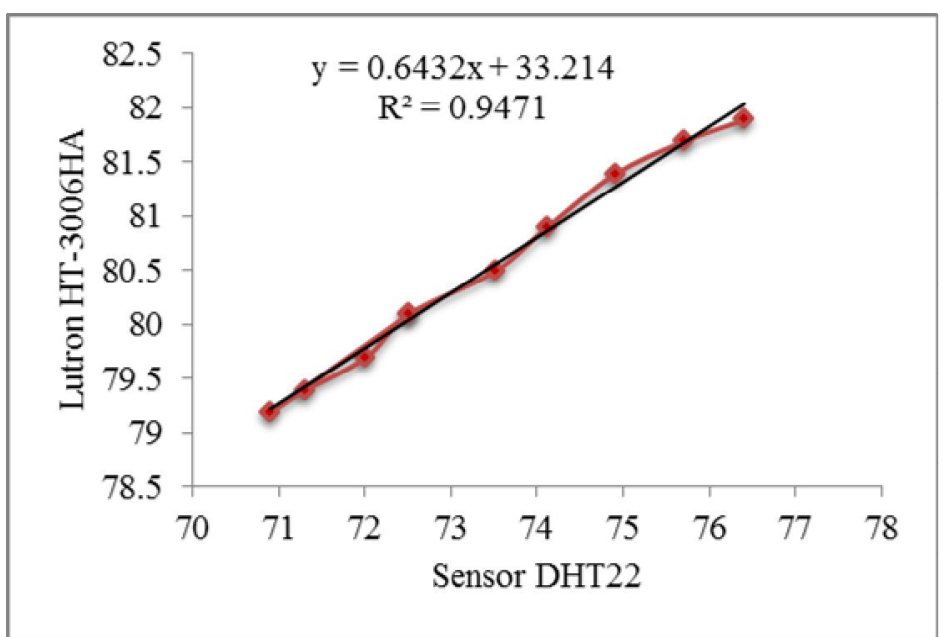

Gambar 6 Grafik perbandingan kelembaban relatif pada kondisi normal

\subsection{Karakterisasi Sensor LDR}

Pengujian pada sensor LDR dilakukan dengan memaparkan sensor LDR secara langsung pada keadaan cahaya alami di dalam ruangan dari waktu ke waktu dengan kondisi cuaca normal. Ruangan yang digunakan pada pengujian ini adalah ruang Laboratorium Elektronika dan Instrumentasi fisika. Pencahayaan alami yang masuk ke dalam ruangan ini cukup baik. Dari pengujian ini diperoleh nilai sensor LDR dan perbandingannya dengan alat ukur intensitas cahaya Lux Meter. Pengukuran dilakukan untuk mengamati rentang nilai sensor LDR yang dibutuhkan untuk memaksimalkan penerangan di dalam ruangan. Hasil pengukuruan dapat dilihat pada Tabel 2. 
Tabel 2 Karakterisasi Sensor LDR

\begin{tabular}{ccccc}
\hline Waktu & Jam & $\begin{array}{c}\text { Resistansi } \\
(\text { Ohm) }\end{array}$ & $\begin{array}{c}\text { Desimal } \\
\text { ADC }\end{array}$ & $\begin{array}{c}\text { Intensitas } \\
\text { Cahaya (Lux) }\end{array}$ \\
\hline \multirow{2}{*}{ Pagi } & 05.00 & 7100 & 58 & 0,0 \\
& 06.00 & 6900 & 96 & 0,0 \\
\multirow{3}{*}{ Siang } & 07.00 & 5800 & 120 & 76,50 \\
& 12.00 & 4600 & 443 & 132,00 \\
& 13.00 & 3400 & 526 & 166,00 \\
Sore & 14.00 & 2700 & 639 & 197,00 \\
& 16.00 & 4300 & 310 & 112,00 \\
& 17.00 & 5900 & 230 & 96,00 \\
Malam & 18.00 & 6100 & 85 & 0,00 \\
& 19.00 & 6800 & 75 & 0,00 \\
& 20.00 & 7300 & 67 & 0,00 \\
& 21.00 & 7500 & 66 & 0,00 \\
\hline
\end{tabular}

Hasil pengujian pada Tabel 2 menjelaskan bahwa nilai pencahayaan di dalam ruangan cukup baik dimana pada saat siang hari nilai maksimal Lux yang terukur adalah 197,00 Lux. Hasil pada perbandingan nilai resistansi LDR tidak linier terhadap perubahan nilai Lux LDR dengan nilai linearitasnya sebesar 0,8483 , nilai kemiringan garis 6,912 dan nilai awalnya sebesar - 6,596. Hal tersebut sesuai dengan kurva karakterisasi LDR, dimana nilai resistansi LDR berkurang dengan bertambahnya intensitas cahaya yang diindra LDR. Berikut tampilan hasil perubahan nilai resistansi LDR.

\subsection{Hasil Pengujian Sistem Kontrol Keseluruhan}

Pengujian alat secara keseluruhan meliputi pengujian pada perancangan hardware dan software rangkain. Dari pengujian sistem secara keseluruhan dapat dilihat apakah perangkat input dan output yang digunakan bekerja dengan baik atau tidak. Hasil pengujian sistem secara keseluruhan dapat dilihat pada Tabel 3.

Tabel 3 Pengujian Sistem Kontrol Keseluruhan

\begin{tabular}{cccccccc}
\hline \multirow{2}{*}{ No } & \multirow{2}{*}{$\begin{array}{c}\text { Resistansi } \\
(\mathbf{O h m})\end{array}$} & $\begin{array}{c}\text { Desimal } \\
\text { ADC }\end{array}$ & \multicolumn{2}{c}{ Sensor DHT11 } & $\begin{array}{c}\text { Relay 1 } \\
\text { (Kipas Angin) }\end{array}$ & $\begin{array}{c}\text { Relay 2 } \\
\text { (Lampu) }\end{array}$ & Gorden \\
\hline 1. & 6900 & 96 & $76,4 \%$ & $26,8^{\circ} \mathrm{C}$ & OFF & ON & Tertutup \\
2. & 3400 & 526 & $74,1 \%$ & $28,8^{\circ} \mathrm{C}$ & ON & OFF & Terbuka \\
3. & 2700 & 639 & $72,5 \%$ & $29,1{ }^{\circ} \mathrm{C}$ & ON & OFF & Terbuka \\
4. & 5900 & 230 & $74,9 \%$ & $28,6^{\circ} \mathrm{C}$ & ON & OFF & Tertutup \\
5. & 6800 & 75 & $75,7 \%$ & $27,0^{\circ} \mathrm{C}$ & ON & ON & Tertutup \\
\hline
\end{tabular}

Intensitas cahaya acuan yang diprogram pada sistem ini adalah 100 Lux atau 500 ADC. Saat nilai pembacaan sensor LDR kecil dari 100 Lux maka sistem bekerja pada kondisi Gorden tertutup, serta menghidupkan lampu (relay $2 \mathrm{ON}$ ). Kemudian saat nilai intensitas cahaya yang diindra besar 100 Lux atau 500 ADC maka sistem akan bekerja dengan membuka gorden dan mematikan lampu (relay $2 \mathrm{OFF}$ ). Suhu acuan yang diprogram pada sistem ini adalah $27^{\circ} \mathrm{C}$ dan acuan kelembaban relatif pada $40 \%$. Saat suhu ruangan berada di atas $27^{\circ} \mathrm{C}$ atau kelembaban ruangan dibawah $40 \%$ maka kipas otomatis hidup untuk mengkondisikan suhu di dalam ruangan.

Berdasarkan Tabel 3 dapat dilihat bahwa sistem buka tutup gorden bekerja dengan baik dan sistem otomatis lampu, serta kipas angin juga bekerja dengan baik. Saat jam 06:00 nilai desimal ADC LDR intensitas cahaya yang didapatkan 96 dengan suhu $26,8^{\circ} \mathrm{C}$ dan kelembaban relatif 76,4\%, maka sistem gorden tertutup dan lampu otomatis hidup serta kipas angin berada pada kondisi mati. Kemudian saat jam 14:00 intensitas cahaya yang diperoleh 639 ADC dengan suhu $29,3^{\circ} \mathrm{C}$ dan kelembaban relatif $72,9 \%$, maka sistem gorden akan terbuka dan lampu secara otomatis akan mati dengan kipas angin menyala untuk mengkondisikan suhu diruangan. Keseluruhan dari mekanisme kerja sistem ini berjalan sesuai dengan program yang telah ditanamkan. 


\section{KESIMPULAN}

Sensor LDR dapat bekerja mendeteksi perubahan intensitas cahaya di luar ruangan. Motor stepper bergerak membuka gorden dan lampu ruangan mati pada saat intensitas cahaya berada di bawah 100 lux atau 500 ADC. Kipas angin aktif pada saat kondisi suhu yang dideteksi sensor DHT22 besar $27^{\circ} \mathrm{C}$ atau kelembaban di bawah $40 \%$. Perubahan suhu dan kelembaban relatif di dalam ruangan yang dideteksi oleh sensor DHT22 saat kondisi suhu normal didapatkan persen error pengukuran suhu sebesar $1,7988 \%$ dan kelembaban relatif sebesar 8,8465\%.

\section{DAFTAR PUSTAKA}

Ahmad, A,N. dan Dharmawan, A., "Purwarupa Sistem Otomasi Buka Tutup Tiras Berbasis Light Dependent Resistor", IJEIS, Universitas Gagjah Mada, Yogyakarta (2011).

Lidiawati, W., Pranoto, L, M., Waslaluddin. dan Hidayat, J., "Otomatisasi Lampu , Tirai, dan Kipas Angin Menggunakan Mikrokontroler untuk Menghemat Energi Listrik, Jurnal Elektronika dan Telekomunikasi”, Universitas Pendidikan Indonesia, Bandung (2013).

Marsidi, C.D. dan Kusmindari., "Pengaruh Tingkat Kelembaban Nisbi Dan Suhu Ruang Kelas Terhadap Proses Belajar", Jurnal Ilmiah TEKNO, Universitas Bina Darma, Palembang (2009).

Menteri Kesehatan Republik Indonesia, Keputusan Menteri Kesehatan Republik Indonesia (KEPMENKES) Nomor 1405/Menkes/SK/XI/2002 Tentang Persyaratan Kesehatan Lingkungan Kerja Perkantoran dan Industri, Jakarta (2002).

Nainggolan, H. dan Yusfi, M., "Rancang Bangun Sistem Kontrol Suhu dan Kelembaban Relatif Pada Ruangan dengan Menggunakan Motor DC Berbasis Mikrokontroler ATMEGA8535", Jurnal Fisika Unand (JFU), Jur. Fisika Unand, Padang (2013). 